\title{
Indications and Long-term Outcomes of Open Augmentation Rhinoplasty with Autogenous L-shaped Costal Cartilage Strut Grafts -A Single Plastic Surgeon's Experience
}

Authors' Contribution: A-Study Design B-Data Collection C-Statistical Analysis D-Data Interpretation E-Manuscript Preparation F-Literature Search G-Funds Collection

\author{
Laura Leach ${ }^{1,2 B D E F}$, Eamon Shamil ${ }^{1,3 B D E F}$, Charles M. Malata ${ }^{1,4 A F}$ \\ 'Department of Plastic and Reconstructive Surgery, Addenbrooke's University Hospital, Cambridge University Hospitals NHS Foundation \\ Trust, Cambridge, UK \\ 2Department of Otorhinolaryngology, Peterborough City Hospital, North West Anglia NHS Foundation Trust, UK \\ 'Department of Otorhinolaryngology, Guy's \& St Thomas' NHS Foundation Trust London, UK \\ ${ }^{4}$ Anglia Ruskin University School of Medicine, Cambridge \& Chelmsford, UK
}

Article history: Received: 25.02.2018 Accepted: 03.04.2018 Published: 30.06.2018

ABSTRACT:

Introduction: We present a single surgeon's experience of open augmentation rhinoplasty with autogenous L-shaped costal cartilage grafts, with long-term patient-reported outcome data. We highlight the salient operative steps and outline the peri-operative care required to optimise outcomes.

Materials and Methods: A retrospective review of eleven such augmentation rhinoplasties performed between 2008 and 2016 was undertaken. Indications included saddle nose deformity [granulomatosis with polyangiitis $(n=7)$ and relapsing polychondritis $(n=1)$ ], post-traumatic nasal collapse $(n=1)$ and advanced cosmetic westernisation of the nose $(n=2)$. Long-term patient-reported outcome was assessed with a patient questionnaire.

Results: All patients achieved marked improvement in nasal position, shape and function. There was no cartilage exposure, warping or resorption and no recurrent deformities. One patient's dorsal graft was fractured two years later during an ophthalmological procedure and the deformity was re-corrected successfully, again with the above technique. Average follow up was 5.2 years. Of the nine patients who responded to the follow-up questionnaire, $100 \%$ were satisfied with their nasal appearance. $100 \%$ of responders at follow-up reported that they have had no problems relating to their nose $(n=9)$.

Discussion: L-shaped costal cartilage grafts provided a reliable, reproducible approach in augmentation rhinoplasty for disparate indications (inflammatory, traumatic and cosmetic) in the hands of a low-volume operator. With careful patient selection and planning, this technique can provide pleasing aesthetic outcomes and high patient satisfaction, with good long-term outcomes.

KEYWORDS: $\quad$ augmentation rhinoplasty, costal cartilage grafts, autoimmune inflammatory disease, granulomatosis with polyangiitis, relapsing polychondritis, screw fixation of grafts

\section{INTRODUCTION}

Granulomatosis with polyangiitis (GP) and relapsing polychondritis (RPC) are both immune-mediated conditions associated with saddle nose deformity with physical, functional and psychological implications. RPC is a multi-systemic inflammatory disease associated with cartilage destruction with an annual incidence of 0.7-3.5 cases per million [1,2]. GP has an incidence of 3-14.4/million per year in Europe and is a multi-systemic necrotising granulomatous vasculitis [3]. It results in inflammation of small and medium sized blood vessels, and subsequent mucosal inflammation. The cycle of inflammation and healing leads to granulation, scar formation, and tissue contracture. This process causes the weakening of the cartilagino- 
us part of the septum, leading to septal perforation, weakening of the middle portion of the nose and a resultant saddle-nose deformity [4]. Symptomatic management of autoimmune-related saddle nose deformities includes nasal saline rinses, intranasal corticosteroids, mucolytics, and emollients for nasal crusting and mucosal-sparing techniques. However, nasal reconstruction is the only definitive treatment of the deformity. Surgical reconstruction of saddle-nose deformities using cartilage grafts has rarely been explored [5].

Nasal deformity secondary to trauma is often initially managed with closed reduction ideally within 10 days of the injury but post-reduction deformity persists in 14-50\% of patients [6]. These patients may require a secondary rhinoplasty for function and/or cosmesis.

African nose westernisation entails the challenge of correcting an acute columellar-labial angle, bulbous and poorly-projecting tip, short columella and flaring alae with rounded nostrils and broad alar bases [7].

The foregoing disparate indications are amenable to correction using similar complex rhinoplasty techniques. We present a single surgeon's experience of performing open augmentation rhinoplasty using autogenous L-shaped costal cartilage dorsal and columellar strut grafts to correct marked nasal deformity secondary to autoimmune conditions, trauma-related injuries to the dorsum of the nose and Westernisation of African noses. Costal-cartilage grafting of the nose is at best a challenging operation, which is not commonly used in aesthetic rhinoplasty surgery; we reflect upon key intra-operative and peri-operative features to optimise outcomes.

\section{MATERIALS AND METHODS}

A retrospective review was undertaken of eleven augmentation rhinoplasties performed between 2008 and 2016 by a single consultant plastic surgeon. Patients were identified using theatre records, the consultant's logbook and electronic billing records. Surgery was performed at a tertiary university teaching hospital and two private hospitals. Patients were followed up in the relevant outpatient clinics. Case notes were reviewed retrospectively, focusing on demographics, cause and severity of deformity, operative indication and technique, complications and cosmetic outcomes.

\section{Surgical technique}

All patients underwent general anaesthesia with endotracheal intubation. An open rhinoplasty approach was used, with

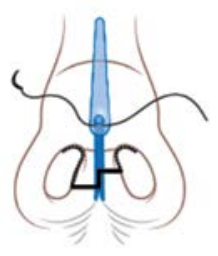

c

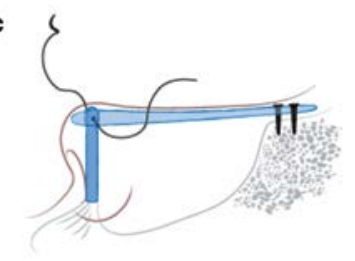

d

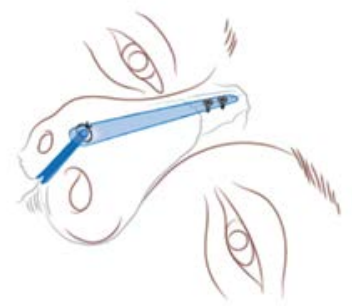

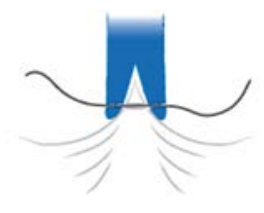

Fig. 1. Artist's illustration showing key stages of the open augmentation rhinoplasty approach using costal cartilage; a) stair-step columellar and infra-cartilaginous (rim) incisions, b) the split columellar strut sitting astride the nasal spine prior to suture fixation of the two via a drill hole through the nasal spine, c) securing the dorsal strut to the nasal bone with monocortical titanium screws. The dorsal and columellar struts are secured to each other using a single 4/O PDS suture, d) the completed open augmentation rhinoplasty with the columellar and dorsal struts in position.

a stair-step transcolumellar incision extending into bilateral infracartilaginous (rim) incisions (Figure 1). After exposure of the lower lateral cartilages, the underlying nasal bones and cartilage remnants were exposed taking care not to breach the mucosa. An additional $1 \mathrm{~cm}$ skin crease incision over the radix was made to allow direct access to the nasal bone cranially. The dorsal cartilaginous and bony structures were examined for damage, followed by rasping and trimming, as necessary, to create a receptive graft bed.

Costal cartilage was harvested from the sixth or seventh rib. Following subperichondrial costochondral harvest, a water test via the valsalva manoeuvre was performed to demonstrate any pleural leaks.

A dorsal (length 3.5-5.0 cm; variable width) and columellar strut (length 2.5-3.5 cm; width $5 \mathrm{~mm}$; height $2-3 \mathrm{~mm}$ ) of cartilage were carved using the balanced forces concept of Gibson and Davis with a focus on symmetry in order to reduce the risk of post-operative warping [9]. The dorsal graft was secured to the nasal bone with two titanium self-tapping monocortical screws (6-8 mm length, Leibinger Wurzburg Miniplating System, Wurzburg, Germany) to ensure a stable and symmetrical reconstruction.

The posterior end of the columellar graft was carefully split 
Tab. I. Patient Characteristics.

\begin{tabular}{|c|c|c|c|c|c|c|c|c|}
\hline PATIENT & GENDER & ACE & $\begin{array}{l}\text { PRIMARY OR } \\
\text { SECONDARY } \\
\text { RHINOPLASTY }\end{array}$ & INDICATION & CO-MORBITIES & $\begin{array}{l}\text { IMMUNOSUPPRESSION AT } \\
\text { SURGERY }\end{array}$ & $\begin{array}{l}\text { FOLLOW-UP } \\
\text { (YEARS) }\end{array}$ & COMPLICATIONS \\
\hline 1 & $\mathrm{~F}$ & 25 & Secondary & GP & None & $\begin{array}{l}\text { Prednisolone 10mg daily } \\
\text { Budesonide nebulisers } \\
\text { 1mg BD }\end{array}$ & 8.7 & none \\
\hline 2 & $\mathrm{~F}$ & 74 & Primary & GP & $\begin{array}{l}\text { Spinal } \\
\text { degeneration } \\
\text { Hypertension }\end{array}$ & $\begin{array}{l}\text { Prednisolone } 1.5 \mathrm{mg} / \text { day } \\
\text { Methotrexate } 22.5 \mathrm{mg} / \\
\text { week }\end{array}$ & 7.7 & $\begin{array}{l}\text { Slow healing on small } \\
\text { area over donor site }\end{array}$ \\
\hline 3 & $\mathrm{~F}$ & 32 & Primary & RPC & None & None & 6.3 & none \\
\hline 4 & M & 30 & Primary & GP & $\begin{array}{l}\text { Crohn's } \\
\text { disease }\end{array}$ & $\begin{array}{l}\text { Presnisolone } 10 \mathrm{mg} / \text { day } \\
\text { Azathioprine } 150 \mathrm{mg} / \text { day } \\
\text { Mesalazine 1g/day }\end{array}$ & 5.2 & none \\
\hline 5 & $\mathrm{~F}$ & 30 & Primary & GP & None & $\begin{array}{l}\text { Prednisolone } 1 \mathrm{mg} / \text { day } \\
\text { Azathioprine } 100 \mathrm{mg} / \text { day }\end{array}$ & 5.2 & none \\
\hline 6 & $\mathrm{~F}$ & 48 & Primary & GP & None & $\begin{array}{l}\text { Rituximab 4-monthly } \\
\text { Methotrexate } 15 \mathrm{mg} / \text { week }\end{array}$ & 3.7 & $\begin{array}{l}\text { Cartilage graft fractured } \\
\text { post } \\
\text { dacryocystorhinostomy }\end{array}$ \\
\hline 7 & $\mathrm{~F}$ & 51 & Secondary & GP & None & $\begin{array}{l}\text { Rituximab infusions } \\
\text { 8-monthly } \\
\text { Methotrexate } 12.5 \mathrm{mg} / \\
\text { week }\end{array}$ & 1.2 & none \\
\hline 8 & $\mathrm{~F}$ & 58 & Primary & GP & $\begin{array}{l}\text { Breast cancer, } \\
\text { gastro- } \\
\text { intestinal } \\
\text { ulcers }\end{array}$ & $\begin{array}{l}\text { Prednisolone } 1 \mathrm{mg} / \text { week } \\
\text { (weaning off at time of } \\
\text { surgery) }\end{array}$ & 3.5 & none \\
\hline 9 & $\mathrm{~F}$ & 22 & Primary & $\begin{array}{l}\text { Westernisation } \\
\text { of African Nose }\end{array}$ & $\begin{array}{l}\text { Mental health } \\
\text { disorder }\end{array}$ & None & 4.6 & $\begin{array}{l}\text { Pseudomonas infection } \\
\text { to radix access incision } 3 \\
\text { weeks post-operatively }\end{array}$ \\
\hline 10 & M & 27 & Primary & $\begin{array}{l}\text { Westernisation } \\
\text { of African Nose }\end{array}$ & $\begin{array}{l}\text { Non-allergic } \\
\text { perennial } \\
\text { rhinitis }\end{array}$ & None & 9.6 & $\begin{array}{l}\text { Painful screw from } \\
\text { rhinoplasty nasal bridge } \\
\text { graft }\end{array}$ \\
\hline 11 & M & 46 & Primary & $\begin{array}{l}\text { Post-traumatic } \\
\text { dorsal collapse }\end{array}$ & Hypertension & None & 6.3 & none \\
\hline Median & & 32 & & & & & 5.2 & \\
\hline
\end{tabular}

by approximately $5 \mathrm{~mm}$ to allow it to sit astride the anterior nasal spine. This was fixed to the nasal spine with a 4/0 PDS suture through a hole drilled in the spine with a $1.5 \mathrm{~mm}$ dental drill (Leibinger Wurzburg Miniplating System, Wurzburg, Germany). The two grafts were then connected to each other using a 'hole and dowel' arrangement and secured with a single 4/0 PDS suture (Figure 1). The overall structure was then examined and the cartilage further trimmed as necessary to improve contour.

After securing the L-shaped graft, the rim columellar incision was closed with 4/0 Vicryl Rapide to the mucosa and 5/0 nylon to the skin. The radix incision was closed in two layers $(5 / 0 \mathrm{Vi}$ - cryl and 6/0 Nylon). Half-inch wound closure strips (3M Steri-Strip) and a thermoplastic external nasal splint were then applied and left in place for 7 days. [8]

\section{RESULTS}

Indications included saddle nose deformity (granulomatosis with polyangiitis $(\mathrm{n}=7)$, relapsing polychondritis $(\mathrm{n}=1))$ post-traumatic nasal collapse $(n=1)$ and advanced cosmetic westernisation of the nose $(n=2)$. The majority were primary rhinoplasties $(n=9)$, but two were revision rhinoplasties (Table 1 ) The median age at operation was 32 , and eight of the eleven 


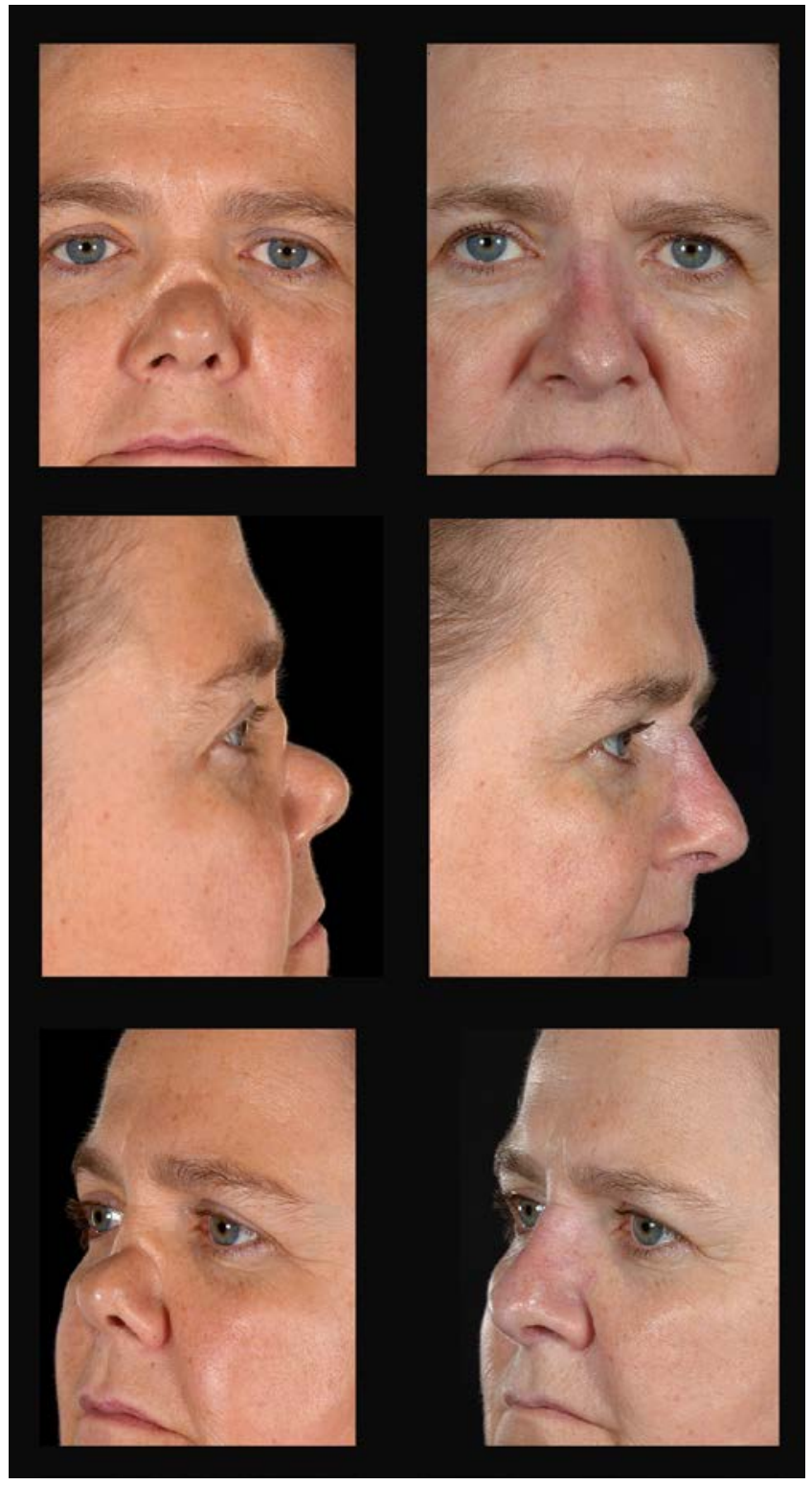

Fig. 2. Pre (left) and three-year postoperative (right) appearances of a patient with a saddle-nose deformity secondary to Cranulomatosis with Polyangiitis (patient 6). Note the correction of the saddle-nose A-frame deformity between the bony and soft tissue part of the nose, elongation of the foreshortened nose and improved dorsal profile. The nose is also straighter in the front view.

rhinoplasties were on caucasian patients. Length of follow-up from the operation date was a median of 5.2 years (average 5.6, range 1.2-9.6).

All patients achieved marked improvement in nasal position and shape (Figures 2-4). There was no cartilage exposure or resorption and no recurrent deformities. There were no incidences of nasal deviation due to cartilage warping. Long-term

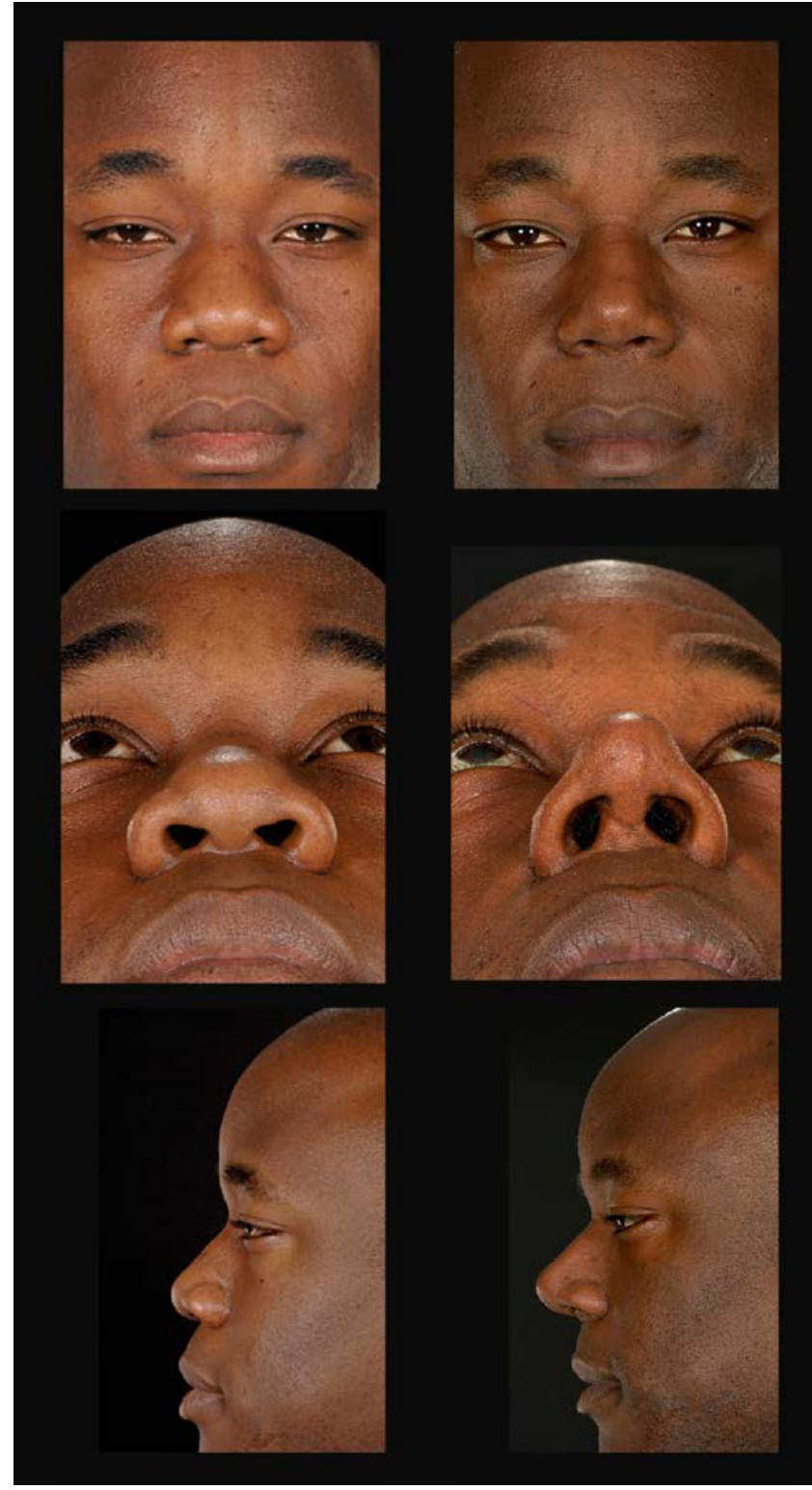

Fig. 3. Westernisation rhinoplasty in a man of mixed ethnicity (patient 9) Postoperative photographs (right side) were taken 6 years after surgery. Note the partially visible V-shaped columellar incision scar, improvement in the bulbous and poorly-projecting tip, and reduction in size of the alar bases. The cartilage grafts refined the tip, improved the projection and straightened the dorsal profile.

patient reported outcome was assessed with a questionnaire at a median of 5.2 years post-operatively. $90 \%$ of patients $(n=9)$ responded, of whom $100 \%$ were satisfied with their nasal appearance. One of these patients (with GP) reported that their nose had some residual nasal dorsal deviation however they felt that it was markedly improved compared to the pre-operative appearance and they were therefore satisfied with the improvement. A second patient with GP stated that they were "hap- 
py enough" with the appearance but reported they had some minor nasal deviation. At follow-up all nine reported that they have had no problems relating to their nose.

Most patients with autoimmune disease did not experience a relapse during this period, however, patient 5 experienced a mild flare in GP symptoms two months post-operatively. Despite requiring the addition of rituximab to her immunosuppression regime, there were no resultant nasal complications. There were no early complications apart from patient 8 who developed a pseudomonas infection of the radix access incision three weeks post-operatively. This was treated successfully with antibiotics and washout, with no permanent sequelae in the 4.6 years of follow-up postoperatively. Patient 9 underwent removal of a persistently painful fixation screw at one year post-operatively, without causing loosening of the dorsal graft (Figure 3). Patient 6 had cartilage graft fracture with deviation to the left two years later during an ophthalmological procedure (dacryocystorhinostomy) and the deformity re-corrected successfully with the above technique using rib cartilage from the contralateral side to that of the primary operation (Figure 4).

There were no donor site surgical complications such as bleeding, pneumothorax, infection or poorly-controlled pain. $\mathrm{Pa}$ tient 2 (on immunosuppression for GP) had a small area over the donor site which was initially slow to heal, however this subsequently healed satisfactorily.

\section{DISCUSSION}

In this study, we have demonstrated that the technique of using L-shaped cartilage grafts can be used successfully for nasal deformity due to a range of pathologies including autoimmune conditions, trauma and cosmetic westernisation of the nose.

The complex nature of these deformities requires a careful consideration of perioperative factors to ensure optimal outcome of augmentation rhinoplasty, and a multidisciplinary perioperative approach is necessary to create a safe and individualised service for patients. Those with autoimmune conditions require specialist input from a rheumatologist to monitor disease progression, and preoperative assessment by an anaesthetist and otolaryngologist to exclude airway pathologies including subglottic and tracheobronchial stenosis [9].

In our experience, with careful patient selection and adequate multidisciplinary optimisation, augmentation rhinoplasty is safe and effective in patients with saddle deformity secondary to GP and RPC. These patients all underwent pre-operative consultations with a specialist rheumatologist who maintained them on a maximum of

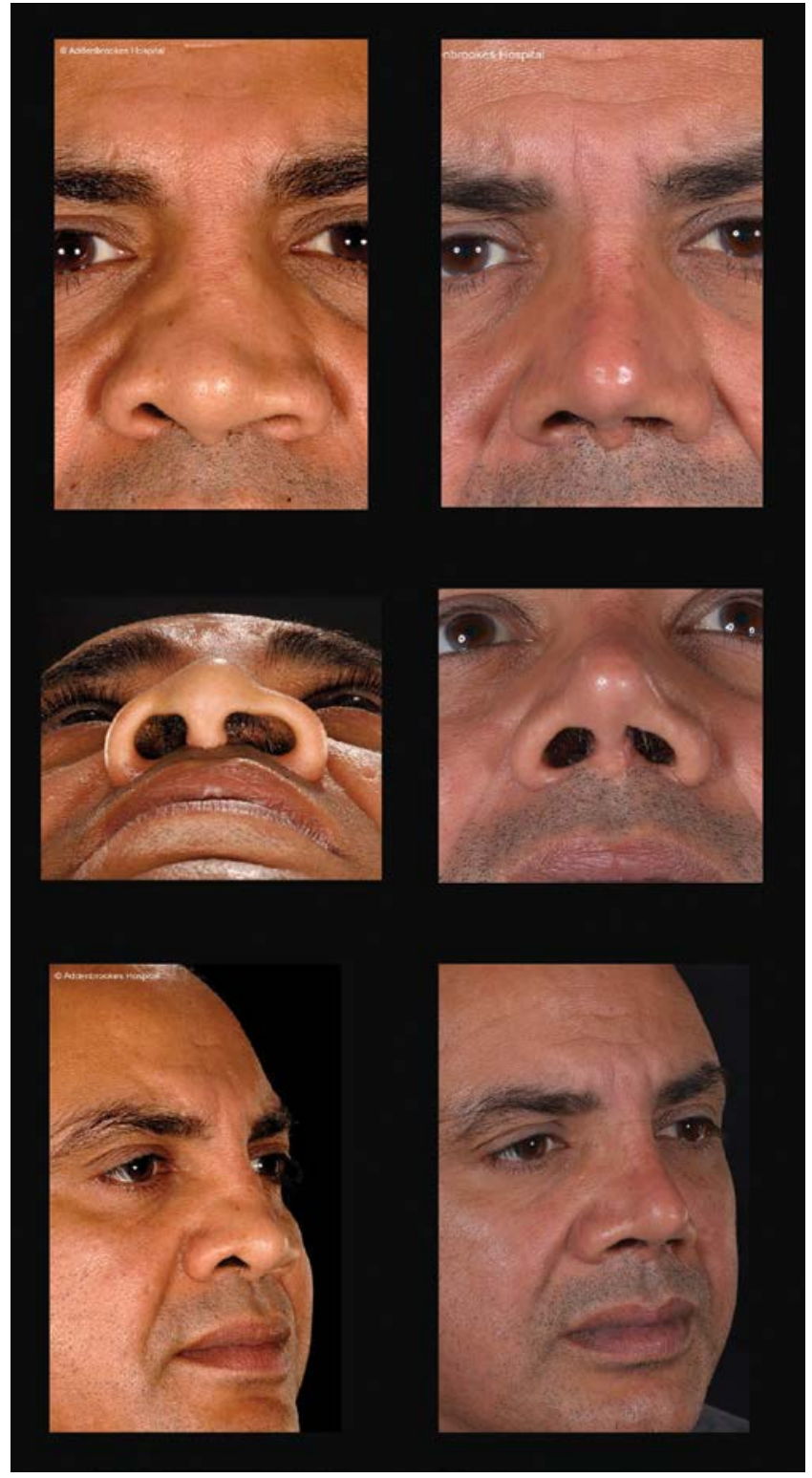

Fig. 4. Open augmentation rhinoplasty with costal cartilage for post-traumatic appearances (patient 10). Post-operative photographs (right) were taken at 5 years. Note the improved dorsal aesthetic lines (AP view), refined tip and nostrils and increased tip projection. With the internal scarring from multiple previous surgeries prior to referral and the complexity of the deformity, it is not surprising that there was still some residual alar and dorsal asymmetry.

10mg prednisolone daily as per local guidelines developed from our joint experience. Postoperatively, patients were given three doses of intravenous dexamethasone to reduce swelling. A further concern regarding operating on patients with autoimmune conditions is the potentially increased risk of infection, secondary to immunosuppressive therapies as well as a chronic microbial colonisation of the nasal epithelium. In our protocol, we address this by prescribing a 
48-hour course of intravenous antibiotics postoperatively and a further seven days of topical antibiotics. Multidisciplinary team preand post-operative medical optimisation of disease is a key factor to successful operative outcomes.

\section{Surgical challenges that have been addressed}

In African and Asian noses there is often inadequate septal cartilage for augmentation rhinoplasty [10]. Furthermore, thickness of the soft tissue envelope means that conchal cartilage grafts are not strong enough and therefore result in insufficient definition and refinement. Our study suggests that costal cartilage grafts may therefore be superior in this patient population.

Traditionally surgeons are cautious to operate on saddle nose deformity in autoimmune conditions due to the potential risk of graft failure secondary to disease flare-up that will result in suboptimal long-term cosmetic results. However, with an average of 5.2 years follow-up of seven patients with autoimmune conditions, we have not seen post-operative recurrence of nasal deformity. To reduce this risk, we only operated on patients that were disease-free for at least one year pre-operatively.

\section{Limitations of the study}

A single surgeon's experience and small numbers limit this study. We will continue to follow-up patients to monitor for disease recurrence longer-term.

\section{Conclusion}

This case series demonstrates that using L-shaped costal cartilage grafts can be a reliable, reproducible approach in augmentation rhinoplasty for disparate indications including for saddle-nose deformity secondary to inflammatory disease, trauma and for cosmetic reasons, in the hands of a low-volume operator. Long-term follow-up showed good outcomes and ongoing high patient satisfaction. Careful patient selection, pre-operative planning and meticulous execution are required.

\section{Ethical considerations}

Informed consent was obtained from all individual participants for whom identifying information is included in this article.

\section{REFERENCES}

1. Hazra N, Dregan A, Charlton J, Gulliford MC, D'Cruz DP: Incidence and mortality of relapsing polychondritis in the UK: a population-based cohort study. Rheumatology, 2015; 54(12):2181-7

2. Kent PD, Michet CJ Jr, Luthra HS: Relapsing polychondritis. Curr Opin Rheumatol., 2004; 16(1):56-61

3. Mahr AD, Neogi T, Merkel PA: Epidemiology of Wegener's granulomatosis: Lessons from descriptive studies and analyses of genetic and environmental risk determinants. Clin Exp Rheumatol., 2006; 24(2 Suppl 41):S82-91

4. N, Rasmussen: Management of the ear, nose, and throat manifestations of Wegener granulomatosis: an otorhinolaryngologist's perspective. Curr Opin Rheumatol., 2001: 13(1):3-11

5. Hernández-Rodríguez J, Hoffman GS, Koening CL: Surgical interventions and local therapy for Wegener's granulomatosis. Curr Opin Rheumatol., 2010; 22(1):29-36

6. Basheeth N, Donnelly M, David S, Munish S: Acute nasal fracture management: A prospective study and literature review. Laryngoscope, 2015; 125(12):2677-84

7. Stucker FJ, Lian T, Sanders K: African American rhinoplasty. Facial Plast Surg Clin North Am., 2005; 13(1):65-72

8. Qian SY, Malata CM: Avoiding pitfalls in open augmentation rhinoplasty with autologous L-shaped costal cartilage strut grafts for saddle nose collapse due to autoimmune disease: The Cambridge experience. J Plast Reconstr Aesthet Surg.,2014; 67(8):e195-203

9. Girard C, Charles P, Terrier B, Bussonne G, Cohen P, Pagnoux C et al: Tracheobronchial Stenoses in Granulomatosis With Polyangiitis (Wegener's): A Report on 26 Cases. Medicine (Baltimore), 2015; 94(32):e1088

10. Kim YK, Kania K, Nguyen AH: Rhinoplasty with Cartilage and Alloplastic Materials, Nasal SMAS Management in Asian Rhinoplasty, Contracture Classification, and Secondary Rhinoplasty with Contracture. Semin Plast Surg, 2015; 29(4):255-261 


\section{Word count: 1650 Tables: 1 Figures: 4 References: 10}

\section{Access the article online: DOI: 10.5604/01.3001.0011.7258 Table of content: https://otolaryngologypl.com/issue/11199}

Corresponding author: Professor Charles Malata, Consultant Plastic Surgeon, Plastic and Reconstructive Surgery Department, Addenbrooke's Hospital, Box 186, Cambridge University Hospitals NHS Foundation Trust, Hills Road, Cambridge, CB2 2QQ, UK; Tel: +44 (0)1223 586672;

E-mail address: charles.malata@addenbrookes.nhs.uk

Copyright (c) 2018 Polish Society of Otorhinolaryngologists Head and Neck Surgeons. Published by Index Copernicus Sp. z o.o. All rights reserved.

Competing interests: The authors declare that they have no competing interests.

Cite this article as: Leach L., Shamil E., Malata C. M.; Indications and Long-term Outcomes of Open Augmentation Rhinoplasty with Autogenous L-shaped Costal Cartilage Strut Crafts-A Single Plastic Surgeon's Experience; Otolaryngol Pol 2018; 72 (3): 26-32 